\title{
Kinship in Britain and beyond from the early modern to the present: introduction
}

\author{
RICHARD M. SMITH*AND NAOMI TADMOR†
}

Contemporary social and medical changes - such as the rising divorce rates and rates of subsequent remarriage, the introduction of new fertility techniques and rising longevity - trigger public debates about kinship, nature and culture. At the same time, 'the master narrative' telling how kinship declined in the course of modernization has been largely rejected by historians. Now, however, 'revisionist' arguments emphasizing longterm continuities in kinship and family ties are also being questioned. It is an appropriate time, therefore, to address anew the question of kinship in Britain from the early modern to the present. This special issue of Continuity and Change emerged from discussions initially held at the Ellen McArthur workshop 'Kinship in Britain and Beyond 500-2000', held in Cambridge in 2005. The workshop was organized by Professor R. M. Smith and Dr Naomi Tadmor and was kindly supported by the British Academy, the Economic History Society and the Cambridge Group for the History of Population and Social Structure.

Four foci for investigation, highlighted at the original workshop, are examined here. The first concerns kinship and demography. The availability and the categories of kin most prevalent varied over time and among different social and age groups. The incidence of remarriage, changing marriage ages, generational lengths, and, more recently, lowered fertility, rising longevity, and the prevalence of divorce have also influenced kin availability. Some of the contributions in this volume specifically investigate the changing reservoirs of kin which people have been

* Department of Historical Geography, University of Cambridge.

$\dagger$ Department of History, University of Sussex. 
able to draw upon and review the causes - and historical changes - of varying demographic processes and their resulting kin sets and networks. The methodologies employed in calibrating kin sets under differing demographic conditions are also of particular interest, as several contributions to this volume suggest.

The next point of focus is the relatively well defined area of the law. The issues at stake here concern changes and continuities in the ways in which kinship ties have been recognised and defined by both secular and ecclesiastical laws. The third addresses the role of kinship in interpersonal relations over time, discussed in the original workshop under the heading 'What do people do with kinship?' Issues examined include the roles of kinship in property transmission and the mediation of patronage; the uses of kinship in processes of social mobility and migration; the significance of kinship in forging notions of identity; the significance of kinship in creating or maintaining conflicts. Lastly, the fourth and related point of focus concerns the role of kinship in social action and its significance in the production and reproduction of social and cultural meanings, including also the very boundaries of kinship groupings and the ways in which it has been possible in different periods to recognise, claim, and co-opt kin and thereby also demarcate boundaries between kin and non-kin.

We would like to express our thanks to Continuity and Change for commissioning this special volume in the aftermath of the workshop and selecting and peer-refereeing its contributions, as well as adding contributions to broaden chronological and cultural scopes. Special thanks are also due to Professor Leonore Davidoff, who greatly contributed to the project, and to Professor Kate Lynch who provided the 'Postscript'. 